\title{
Predictors of Appropriate Shocks and Ventricular Arrhythmia in Indonesian with Brugada Syndrome
}

\author{
Ardian Rizal1, Sunu B Raharjo2, Dicky A Hanafy2, Yoga Yuniadi2
}

\begin{abstract}
Background : Brugada syndrome is an inherited disease characterized by an increased risk of sudden cardiac death owing to ventricular arrhythmias in the absence of structural heart disease. It has been reported that this syndrome is more prevalent in South-East Asia than in Western countries. Furthermore, genetic studies showed important contributions of several gene mutations to the phenotype of $\mathrm{BrS}$. These suggest that ethnic difference play significant roles in the pathogenesis of BrS. In addition, ICD implantation remains the cornerstone management with a low rate of appropriate shocked. Therefore, it is important to investigate patients' characteristics for risk stratification. Our objective to investigate the clinical, electrocardiography (ECG) and electrophysiological characteristics that can be used as a predictor of appropriate shock due to ventricular arrhythmia (VA) in Indonesian patients with $\mathrm{BrS}$.

Methods: We analyze data from Brugada syndrome registry at National Cardiovascular Centre Harapan Kita from January 2013 until September 2016. Total of 22 patients was included. Characteristics of BrS that we analyzed were baseline characteristics (age and sex), Clinical finding (syncope, cardiac arrest), ECG finding (spontaneous type I or drug induced) and Electrophysiology study result (inducible VA and RV ERP). We also added some new ECG characteristic (S wave in lead I, S wave duration in VI, Fragmented QRS, Junction ST elevation and early repolarization pattern in inferolateral) to be analyzed. Our end point is appropriate shock during ICD interrogation for those who have been implanted an ICD and documented VA for those who didn't receive ICD.

Results: We found a high incidence of appropriate ICD's shock in our population (50\% in our study vs $5-1 \mathrm{I} .5 \%$ in the real world). Predictors of appropriate shock and documented VA are history of syncope $(p=0.045)$, spontaneous type-I ECG $(p=0.0437)$ and right ventricular effective refractory period (RV ERP) of $<200 \mathrm{~ms}(p=0.018)$. Other parameters that have been reported to correlate with the occurrence of VA (S Wave in lead I $(p=0.433)$, early repolarization pattern $(p=0.462)$, fragmented QRS $(p=0.460), S$ Wave duration $(p=0.365)$ and J Point STE $(p=0.800)$ were found to be not correlated to appropriate shock in our populations.

Conclusion: History of syncope, spontaneous type-I Brugada ECG and RV ERP of $<200$ ms have predictive values for risk stratification of Indonesian patients with Brugada syndrome.
\end{abstract}

(Indonesian J Cardiol. 2019;40:243-248)

Keyword: Brugada, Arrythmia, predictor.

\footnotetext{
I Department of Cardiology and Vascular Medicine, Faculty of Medicine, Brawijaya University

${ }^{2}$ Department of Cardiology and Vascular Medicine, Faculty of Medicine, Indonesia University

\section{Correspondence:}

Sunu B Raharjo, MD, PhD

Department of Cardiology and Vascular Medicine, Faculty of

Medicine, Indonesia University

E-mail: Sunu.b.raharjo@gmail.com
}

\section{Introduction}

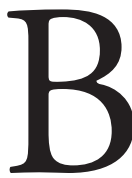

rugada syndrome $(\mathrm{BrS})$ is highly correlated with the unpredicted event of Sudden Cardiac Death (SCD) due to ventricular fibrillation (VF) (1). Found in patients with seemingly structurally normal hearts. It has hallmark ECG sign of coved ST-segment elevation in V1 until V3 
(right precordial lead) ${ }^{(2)}$. It categorized as genetically inherited disorders and characterized with specific gene mutations. SCN5A is the first site of mutation that had been found. SCN5A manage the sodium channels, that had an important role in cardiac cell depolarization. In recent years, $>100$ mutations have been reported $(3,4)$. By manipulating the alpha subunit of the sodium channels it causes spatial dispersion of the epicardial and endocardial depolarization (5). The prevalence of $\mathrm{BrS}$ relatively unique, it has a low prevalence in a western country. But higher in Asian. It is reported that the prevalence was $1.2 \%$ in Japan, $0.17 \%$ in Filipinos, $0.13 \%$ in Taiwanese, $0.9 \%$ in Korean and $3.1 \%$ in Singaporean ${ }^{(1,6)}$. Ethnic-related genetic polymorphisms believed to take responsibility to that different. ${ }^{7}$

Implantable Cardiac Defibrillator (ICD) remains the cornerstone management to avoid sudden death. While the role of Radiofrequency (RF) ablation in $\mathrm{BrS}$ are still debatable. The incidence of appropriate shock in a patient with ICD is relatively low, from a various study it ranges from 5-11.5\%.In the recent metanalysis that published in AHA 2019 involving a large number of patient (1500 patients) with the ICD as a primary prevention, the appropriate ICD shock was delivered in $18 \%$ patient. Not too high, moreover if we compared with the inappropriate ICD shock rate that as much as $15 \%$ of all patient. Concern to choose which patients who are at risk and deserved ICD implantation is remain the subject of interest of $\mathrm{BrS}$ management.

In the era of universal health coverage in Indonesia, it becomes urgently needed our own risk stratification for $\mathrm{BrS}$. So we can get the larger benefit of the ICD implantation and reducing the inappropriate implantation and inappropriate ICD's shock. We combine several patient characteristics that can be used as predictors from the various study. We put it all together and trying to get the best predictors for our Indonesian's specific subset of the patient.

\section{Methods}

\section{Study Design and Patient Selection}

This is an observational retrospective study. We analyze data from Brugada syndrome registry at National Cardiovascular Centre Harapan Kita from January 2013 until September 2016. Data were taken from medical record investigation. Patient ICD's record reinvestigation was performed if needed. The median follow up period were 27 months. Patients with incomplete medical records and incomplete follow up after the diagnosis was excluded.

\section{Predictor Characteristics}

Characteristics of $\mathrm{BrS}$ that we analyzed were a combination of clinical, ECG finding and EP study result characteristics. Baseline characteristics such as age and sex were included. Another clinical finding, history of syncope and cardiac arrest also counted.

Characteristics of ECG finding were reviewed and classified, whether its Spontaneous type 1 ECG pattern (according to consensus criteria) or not. For type 2 and type 3 ECG pattern, we performed a provocation test (using ajmaline). We also included some ECG predictor that has been proposed by another study before, such as:

- $S$ wave in lead 1 divined as an $S$ wave amplitude $\geq$ $0.1 \mathrm{mV}$ and duration $\geq 40 \mathrm{~ms}$

- $\quad S$ wave duration in V1

- Fragmented QRS divined as numerous morphologies of the QRS wave with or without a $Q$ wave, which had the presence of an additional $R$ wave ( $R$ ') or notching in the nadir of the $R$ wave or the $S$ wave, or the presence of $>1$ R' (fragmentation) in 2 contiguous leads

- J Junction ST elevation, we measured ST-segment elevation in leads V1 and V2 because there is usually a prominent $r$ ' in Brugada syndrome and either of these 2 leads shows the maximum ST-segment elevation

- Early repolarization pattern in inferolateral characterized by an elevation of the J-point, either as QRS slurring or notching of $\geq 0.1 \mathrm{mV}$ in $\geq 2$ consecutive inferior leads (II, III, and aVF) or lateral leads (I, aVL, V5, and V6)

Electrophysiology study result that used for data analysis are :

- Right, Ventricular Effective Refractory Period (RV ERP), classified as $\leq 200 \mathrm{~ms}$ or not. We used a standard protocol to evaluate the ERP, using programmed ventricular stimulation.

- Ventricular arrhythmia (VA) Inducibility, any sustained VA that induced by standard protocols of ventricular extra stimulation pacing (S1 until S4). 
Our end point is at least one episode of ventricular arrhythmia (VA) that noted during ICD interrogation or at least one ICD therapy (shock or Anti Tachycardia Pacing) for those who have been implanted an ICD and documented VA or SCD for those who didn't receive ICD.

\section{Data Analysis}

Statistical analyses were done by statistical software SPSS. Continuous variables are reported as mean standard deviation. Categorical variables are reported as number (percentage).

\section{Results}

A total of 28 consecutive patient that was being diagnosed as Brugada Syndrome since January 2013. Seven patient was confirmed has type 1 Brugada ECG pattern, while another 21 has type 2 and 3 Brugada ECG pattern. From those who had type 2 and 3, 6 patients were excluded, because the result of provocation test was negative, and no further follow up was found. The final study population was 22 patients. Most are male, 19 patients $(86,36 \%)$ and ranged from 27 to 55 years old.

\section{Clinical characteristic}

During follow up, seven patients $(31.8 \%)$ proceeded to undergone ICD implantation. While another is treated conventionally. ICD interrogation performed periodically or whenever they had suggestive symptoms. From those who had ICD implanted, 4 patient known to be had VA event in their ICD's interrogation. And all of the events successfully treated by their ICD (with ATP/Anti Tachycardia Pacing or defibrillation). From all ICD that has been implanted no inappropriate ICD's shock was detected.

Another group that didn't get ICD (14 patients) were also being monitored. Careful medical record follows up were performed. None of them are had any VA or SCD event during follow up period.

Clinical characteristics. Significant difference only found in the history of Syncope. History of previous syncope had strong correlation with the occurrence of ICD shock or Ventricular arrhythmia $(p=0.045)$. While another clinical predictors such as sex Male $(\mathrm{p}=$
$0.460)$; age $(\mathrm{p}=0.365)$; palpitation $(\mathrm{p}=0.246)$; family history of SCD ( $0=0.397)$ didn't had significance relationship with ICD's shock / VA.

Table 1. Patient's clinical characteristics as a predictor of ICD Shock or Ventricular Arrhythmia

\begin{tabular}{|c|c|c|c|}
\hline \multirow[t]{2}{*}{ Variables } & \multicolumn{2}{|c|}{$\begin{array}{c}\text { Event } \\
\text { (ICD Shock / Ventricular } \\
\text { Arrhythmia) }\end{array}$} & \multirow[t]{2}{*}{ P value } \\
\hline & Yes $(n=4)$ & No $(n=18)$ & \\
\hline Sex : Male & $4(100 \%)$ & $15(83.33 \%)$ & 0.460 \\
\hline Age & $50.25 \pm 4.85$ & $44.17 \pm 12.70$ & 0.365 \\
\hline History of Syncope & $4(100 \%)$ & $7(38.89 \%)$ & 0.045 \\
\hline Palpitation & $2(50 \%)$ & $4(22.22 \%)$ & 0.246 \\
\hline $\begin{array}{c}\text { Family History of } \\
\text { SCD }\end{array}$ & $1(25 \%)$ & $2(1.22 \%)$ & 0.397 \\
\hline
\end{tabular}

\section{ECG Characteristics}

There are six ECG characteristics that we had analyzed. Type 1 Brugada ECG pattern had a strong correlation with the occurrence of ICD shock / VA in the future $(p=0.005)$. Another five new ECG characteristics found that there was no significant correlation with our endpoint. $S$ wave in lead 1 ( $p=0.433$ ), $S$ wave duration in V1 $(p=0.392)$, fragmented QRS $(p=0.460)$, J Junction ST elevation ( $\mathrm{p}=0.80)$ and infero-lateral early repolarization pattern $(\mathrm{p}=0.462)$.

Table 2. ECG characteristics as a predictor of ICD Shock or Ventricular Arrhythmia

\begin{tabular}{|c|c|c|c|}
\hline \multirow[t]{2}{*}{ Variables } & \multicolumn{2}{|c|}{$\begin{array}{c}\text { Event } \\
\text { (ICD Shock / Ventricular } \\
\text { Arrhythmia) }\end{array}$} & \multirow[t]{2}{*}{$P$ value } \\
\hline & Yes $(n=4)$ & No $(n=18)$ & \\
\hline $\begin{array}{l}\text { Type } 1 \text { Brugada } \\
\text { ECG Pattern }\end{array}$ & $4(100 \%)$ & $3(16.67 \%)$ & 0.0043 \\
\hline$S$ wave in lead 1 & $1(25 \%)$ & $316.67 \%)$ & 0.433 \\
\hline$S$ wave duration in V1 & $\begin{array}{c}0.053 \pm \\
0.011\end{array}$ & $0.044 \pm 0.016$ & 0.392 \\
\hline fragmented QRS & $1(25 \%)$ & $4(22.22 \%)$ & 0.460 \\
\hline $\begin{array}{l}\text { J Junction ST } \\
\text { elevation }\end{array}$ & $1.33 \pm 0.57$ & $1.44 \pm 0.68$ & 0.800 \\
\hline $\begin{array}{c}\text { Early repolarization } \\
\text { pattern }\end{array}$ & $0(0 \%)$ & $3(16.67 \%)$ & 0.460 \\
\hline
\end{tabular}




\section{Electrophysiology Study Result}

Electrophysiology Study (EPS) was focused mainly on 3 things. The first is VA inducibility during EPS. Inducible VA defined as sustained Ventricular Tachycardia (VT) with hemodynamically stable for more than 30 second or any VT/VF with hemodynamically unstable that need electrical defibrillation. The second things that being analyzed were a number of extra stimuli to produce the VA event. And the third was the effective Refractory Period of the RV (RV ERP).

VA was induced in 5 patients, but there was no significant difference between the two groups. Those who will have any VA/SCD event in the future, VA was induced in 2 patients (40\%). And $3(60 \%)$ in patients that will not have any event in the future $(\mathrm{p}=0.234)$. Number of extra stimuli to produce the VA was also not statistically significant $(\mathrm{p}=0.120)$.

While patient that will have any VA/SCD event during follow up period had significantly $(\mathrm{p}=0.018)$ lower RV ERP value $(190.0 \pm 0.01 \mathrm{~ms})$ compared to those who will not have any event $(222.5 \pm 14.80 \mathrm{~ms})$.

\section{Discussion}

Overall sudden cardiac events rate during follow up in this study are 4 out of $22(18.18 \%)$. It was higher if compared to another study. Such as study by Brugada et all 2003, the cardiac events rate is only 45 of the 547 individuals (8.2\%). PRELUDE study, the large registry that published in 2012, also had lower cardiac events rate 14 of 208 ( $4.5 \%)$. But it's comparable to the recent meta-analysis, the ICD's shock delivered in the $18 \%$ of the population. Larger incidence of events rate can be caused by several factors. It had been told that the Asian region had a slightly higher prevalence of $\mathrm{BrS}$, it may contribute to a higher incidence of cardiac events too (8). The other factors may be due to too selective cases selection. As we know, our center (NCCHK) is tertiary/ top referral cardiac center, it means cases are naturally had been selected.

The most important thing in $\mathrm{BrS}$ management is defining which patient will get the benefit of The ICD implantation since it was still the only cornerstone management to date. For cardiac arrest survivor, ICD implantation as secondary prevention is had no doubt $(9,10)$. The grey area laid in primary prevention. We try to combine all $\mathrm{BrS}$ characteristics that previously found to be had a correlation with the incidence of SCD, ventricular arrhythmia or ICD's appropriate shock in the future. From all modalities, from clinical characteristics to sophisticated Electrophysiology Study result.

From clinical characteristics, we found that only the history of the previous syncope is the predictor of VA or SCD during follow up. This finding similar to several previous studies. Patients with symptoms (syncope of unknown origin) and spontaneous coved-type STsegment elevation are at risk for future arrhythmic events. However, risk stratification in asymptomatic cases is still not defined.

Although it was well known that male sex and family history of $\mathrm{BrS}$ was found previously to have an important part in the diagnostic process, we found that it didn't have any correlation with future arrhythmia event. It can be said that making a diagnosis and making risk stratification for $\mathrm{BrS}$ is two different things.

The Result of this study is quite similar to other previous large studies. Compared to two well-known previous studies, PRELUDE and study by Brugada et all 2003. History of syncope and spontaneous type 1 ECG pattern are two characteristics that meet all the

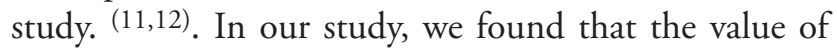
RV ERP can be used as a predictor of a future cardiac event. The lower value of RV ERP and not the inducible arrhythmia had a higher probability of future cardiac events. It is matched to PRELUDE. While f-QRS that proven to be had a correlation in PRELUDE, we found that it not statistically significant.

\begin{tabular}{ccc}
\hline This Study & Brugada et al, 2003 & PRELUDE registry \\
History of Syncope & History of Syncope & History of Syncope \\
Spontaneous Type 1 & Spontaneous Type 1 & Spontaneous Type 1 \\
Brugada ECG & Brugada ECG & Brugada ECG \\
RV ERP & VT/VF inducibility & f-QRS \\
& during EPS & \\
\hline
\end{tabular}

\section{Conclusion}

A patient who had a higher probability of future cardiac events are patient with spontaneous type 1 BrS ECG pattern, history of syncope and lower RV ERP result during EP study. Those are patient subsets that are believed to had the most benefit of ICD implantation as primary prevention. 


\section{Study Limitation}

This study has several limitations. First, a small number of patients that being followed up and being implanted with an ICD. Second, we can't provide additional data that may be useful in the analysis, such as concomitant rhythm disorders, structural heart disease, and gene analysis.

\section{Ethical Clearance}

This study was approved by the institution's ethic committee.

\section{Conflict Of Interest}

None

\section{Publication Agreement}

The authors of this article give permission to Indonesian Journal of Cardiology to publish this article if this article is accepted

\section{Funding}

Self funded

\section{List of Abbreviations}

BrS Brugada Syndrome

ICD : Implantable Cardioverter Defibrillator

ERP : Effective Refractory Periods

VA : Ventricular Arrhythmia

VF : Ventricular Fibrillation

VT : Ventricular Tachycardia

\section{References :}

1. Pappone, C., Brugada, J., Vicedomini, G., Ciconte, G., Manguso, F., Saviano, M., Vitale, R., Cuko, A., Giannelli, L., Calovic, Z. and Conti, M., 2017. Electrical substrate elimination in 135 consecutive patients with Brugada syndrome. Circulation: Arrhythmia and Electrophysiology, 10(5), p.e005053

2. Gehi AK, Duong TD, Metz LD, Gomes JA, Mehta D. Risk stratification of individuals with the Bruga- da electrocardiogram: a meta-analysis. J Cardiovasc Electrophysiol. 2006;17:577-583

3. Robst V, Denjoy I, Meregalli PG, Amirault JC, Sacher F, Mansourati J, Babuty D, Villain E, Victor J, Schott JJ, Lupoglazoff JM, Mabo P, Veltmann C, Jesel L, Chevalier P, Clur SA, Haissaguerre M, Wolpert C, Le MH, Wilde AA. Clinical aspects and prognosis of Brugada syndrome in children. Circulation. 2007;115:2042-2048

4. Saffitz, J.E.Structural heart disease, SCN5A gene mutations, and Brugada syndrome: a complex menage a trois. Circulation. 2005;112:3672-3674

5. Antzelevitch C. (2007). Role of spatial dispersion of repolarization in inherited and acquired sudden cardiac death syndromes. American journal of physiology. Heart and circulatory physiology, 293(4), H2024-H2038.

6. Vutthikraivit, W., Rattanawong, P., Putthapiban, P., Sukhumthammarat, W., Vathesatogkit, P., Ngarmukos, T., \& Thakkinstian, A. (2018). Worldwide Prevalence of Brugada Syndrome: A Systematic Review and Meta-Analysis. Acta Cardiologica Sinica, 34(3), 267-277.

7. Priori SG, Napolitano C, Gasparini M, Pappone C, Della BP, Giordano U, Bloise R, Giustetto C, De NR, Grillo M, Ronchetti E, Faggiano G, Nastoli J. Natural history of Brugada syndrome: insights for risk stratification and management. Circulation. 2002;105:1342-1347

8. Aizawa Y. (2016). Brugada Syndrome:Risk Stratification And Management. Journal of atrial fibrillation, 9(3), 1507.

9. Zipes, D. P., Camm, A. J., Borggrefe, M., Buxton, A. E., Chaitman, B., Fromer, M., ... \& Roden, D. M. (2006). ACC/AHA/ESC 2006 guidelines for management of patients with ventricular arrhythmias and the prevention of sudden cardiac death-executive summary: a report of the American College of Cardiology/American Heart Association Task Force and the European Society of Cardiology Committee for Practice Guidelines (Writing Committee to Develop Guidelines for Management of Patients With Ventricular Arrhythmias and the Prevention of Sudden Cardiac Death). Journal of the American College of Cardiology, 48(5), 1064-1108

10. Shen, W. K., Sheldon, R. S., Benditt, D. G., Cohen, M. I., Forman, D. E., Goldberger, Z. D., ... \& Ol- 
shansky, B. (2017). 2017 ACC/AHA/HRS guideline for the evaluation and management of patients with syncope: a report of the American College of Cardiology/American Heart Association Task Force on Clinical Practice Guidelines and the Heart Rhythm Society. Journal of the American College of Cardiology, 70(5), e39-e110.

11. Priori, S. G., Gasparini, M., Napolitano, C., Della Bella, P., Ottonelli, A. G., Sassone, B., ... \& De Nardis, R. (2012). Risk stratification in Brugada syndrome: results of the PRELUDE (PRogrammed ELectrical stimUlation preDictive valuE) registry. Journal of the American College of Cardiology, 59(1), 37-45.

12. Meng, L., Letsas, K. P., Baranchuk, A., Shao, Q., Tse, G., Zhang, N., ... Liu, T. (2017). Meta-analysis of Fragmented QRS as an Electrocardiographic Predictor for Arrhythmic Events in Patients with Brugada Syndrome. Frontiers in physiology, 8, 678. 